\title{
PERFORMANCE MEASUREMENT IN FIRMS WITH DECENTRALIZED RISK MANAGEMENT AND A RISK-AVERSE BOARD
}

\author{
Marta Michaelis, University of Goettingen, Goettingen, Germany
}

dx.doi.org/10.18374/EJM-21-1.1

\begin{abstract}
Risk management is often a legal requirement for listed firms and is a recommended part of corporate governance. It differs from other managerial activities, but its incentivization has not been extensively discussed in literature. To fill this gap, I model a firm under LEN assumptions, with a risk-averse board and a single business unit that employs a risk manager, stylizing a decentralized risk management system. Contracts of the risk-averse managers are based on performance measures correlated with the firm's outcome; risk management decreases the variances of both metrics. Due to the complexity of the results, I propose the use of simulated correlation coefficients as an alternative to comparative statics. The analysis indicates the existence of contradictory effects of the measure's precision: business unit (risk) managers are better incentivized with more (less) precise measures. Still, more precise measures are preferred in contracts, as they attain higher utility in equilibrium, even while reporting higher risk. The results suggest that incentivizing risk managers with the same profit-based measures as other managers may be suboptimal; therefore, diverging or unique contracting metrics must be found for risk managers.
\end{abstract}

Keywords: risk management; incentives; monitoring; performance measurement; simulation 